\title{
Adaptasi perubahan spektrum SMK 2016 oleh guru SMK Program Keahlian Teknik Konstruksi dan Properti
}

\author{
Ahmad Rifqi Asrib ${ }^{1}$, Anas Arfandi $^{2}$ \\ ${ }^{1,2}$ Fa kultas Teknik, Universitas Negeri Makassar
}

\begin{abstract}
This activity aims to increase the understanding of teachers of the Department of Building Engineering a SMK 4 Gowa about irriga tion and its buildings. The method used in this community partnership program, the mentoring method and the participatory rural approach (PRA) method. Mentoring meth od a re u sed to im prove tea chers' understanding of irriga tion networks and irriga tion structures. The PRA method is carried out to arouse the partner's sense of belonging to the product to be developed, and the partner's sense of resp on sibility to wards the product a nd the environment a round it. The initial survey was conducted to see the extent of respondents' in itial understanding prior to the implementation of PKM on the understanding and ability of teachers to understand the material to be provided. After the PKM implementation activities, the survey wa s a gain conducted to measure the level of understanding of respondents after the implementation of the PKM activities and to be a measure of the effectiveness of theimplementation of the PKM to vocational teachers in the construction and property engineering expertise program. The results of the activity show that most teachers haveonly understood the irrigation material in the Fa ir ca tegory. There is even a n a verage of 12 percent of teachers whose understanding is still la cking. The teachers a lso have notbeen able to distinguish irriga tion buildings very well. After the implementation of the PKM activity, the teachers participating in the activity ex perienced a very significant increase in understanding. Teachers' understanding of the category was very good at $4.36 \%$ to $41.28 \%$. Good category from $20.00 \%$ to $55.64 \%$ even after the activity, all teachers had understood the materia la bout irriga tion and its buildings.
\end{abstract}

Key words: construction and property en gineering expertise program, vocational teachers, irrigation structures

\section{PENDAHULUAN}

Sekolah Menengah kejuruan (SMK) merupakan salah satu lembaga pendidikan formal yang mempersiapkan siswa dan lulusannya sebagai tenaga kerja tingkat menengah dan berpotensi untuk menghasilkan sumber daya manusia (SDM) yang berkualitas. Lembaga ini juga diharapkan mengakomodir kebutuhan pasar yang sering disebut sebagai demand driven. Kehadiran SMK juga meningkatkan ekonomi masyarakat baik pada tingkat lokal, regional, dan nasional. Keunggulan lokal juga menjadi modal dalam meningkatkan daya saing bangsa (Hadi, Andrian, dan Kartowagiran 2019; Purnamawati 2018).

Lulusan SMK diharapkan tidak hanya unggul di daerah saja, tetapi dengan mengoptimalkan kekuatan sistem yang dimiliki maka tamatan SMK juga diharapkan memiliki keunggulan kompetitif di pasar nasional maupun internasional. Karena itu, kurikulum SMK terus diperbaharui seiring dengan dinamika yang terjadi di dunia usaha (Nilasari dan
Dasining 2018; Retnawati, Hadi, dan Nugraha 2016).

Prinsip diversifikasi dalam pengembangan Kurikulum SMK berorientasi pada jenis-jenis bidang pekerjaan atau keahlian yang berkembang dan dibutuhkan di dunia kerja. Daftar jenis-jenis bidang pekerjaan atau keahlian itu yang di lingkungan pendidikan menengah kejuruan dikenal dengan sebutan Spektrum Keahlian Pendidikan Menengah Kejuruan. Spektrum ini adalah jenisjenis program pendidikan serta rambu-rambu penyelenggaraannya, sebagai acuan dalam membuka dan mengembangkan program pendidikan pada SMK (Arfandi and Sampebua 2018).

Jenis-jenis program pendidikan pada Spektrum Keahlian diorganisasikan dalam bentuk Bidang Keahlian, Program Keahlian, dan Kompetensi Keahlian. Spektrum Kurikulum SMK tahun 2016 merupakan revisi dari Spektrum Kurikulum 2013 yang disesuaikan/diselaraskan dengan tuntutan perkembangan kurikulum, ilmu pengetahuan, teknologi, dan kebutuhan dunia kerja sebagai 
acuan dalam pembukaan dan penyelenggaraan bidang/program/kompetensi keahlian pada SMK mulai tahun pelajaran 2017/2018 (Asrib dan Arfandi 2017; Widiaty 2013).

Dampak dari konversi Spektrum 2013 ke Spektrum 2016 terhadap Kompetensi Keahlian yaitu: 1) Perubahan Kompetensi Keahlian Lama menjadi Kompetensi Keahlian Baru; 2) Perubahan Nama Kompetensi Keahlian; 3) Perubahan Program 3 Tahun menjadi Program 4 Tahun; 4) Penggabungan Kompetensi Keahlian; 5) Kompetensi Keahlian Yang Dihilangkan; 6) Kompetensi Keahlian lama sama dengan Kompetensi Keahlian Baru.

Perubahan yang terjadi pada program keahlian Teknik Konstruksi dan Properti terjadi pada Kompetensi Keahliannya antara lain: 1) Paket Keahlian Teknik Konstruksi Baja dan Paket Keahlian Teknik Plambing dan Sanitasi menjadi Kompetensi Keahlian Konstruksi Gedung Sanitasi dan Perawatan bagi SMK Program 4 tahun; 2) Paket Keahlian Teknik Konstruksi Kayu menjadi Kompetensi Keahlian Konstruksi Jalan, Irigasi, dan Jembatan bagi SMK Program 4 tahun; 3) Paket Keahlian Teknik Konstruksi Batu dan Beton menjadi Kompetensi Keahlian Bisnis Konstruksi dan Properti bagi SMK Program 3 tahun; dan 4) Paket Keahlian Teknik Gambar Bangunan menjadi Kompetensi Keahlian Desain Pemodelan dan Informasi Bangunan bagi SMK Program 3 tahun.

Perubahan nama tersebut diikuti dengan perubahan mata pelajaran dari setiap kompetensi keahlian. Salah satu mata pelajaran yang memerlukan adaptasi oleh guru ialah mata pelajaran yang membahas tentang irigasi dan bangunan irigasi. Guru yang selama ini belum pernah mendapatkan materi mengenai irigasi pasti akan mengalami kesulitan dalam membawakan materi pelajaran tersebut. Untuk itu, kehadiran kegiatan program kemitraan masyarakat yang dilakukan adalah membantu para guru SMK Program Keahlian Teknik Konstruksi dan Properti dalam beradaptasi pada perubahan spektrum SMK tersebut terutama pada materi pelajaran mengenai irigasi.

\section{METODE PELAKSANAAN}

Kegiatan Program Kemitraan Masyarakat (PKM) ini dilakukan dengan empat metode, yaitu ceramah, diskusi, tanya jawab, dan observasi. Metode ceramah, diskusi, dan tanya jawab dilakukan pada saat pemberian materi, sedangkan pada saat kunjungan lapangan keempat metode tersebut dilaksanakan. Kegiatan PKM dibagi atas sepuluh tahapan kegiatan. Seluruh kegiatan penjelasan materi teori dan materi latihan dilaksanakan selama 5 kali pertemuan. Adapun rangkaian kegiatan yang dilakukan adalah sebagai berikut:

1. Persiapan pelaksanaan kegiatan dengan menyiapkan administrasi perijinan dan koordinasi dengan mitra kegiatan, serta persiapan segala peralatan dan bahan yang akan digunakan untuk pelatihan.

2. Pelaksanaan pre-tes kepada peserta untuk mengetahui kemampuan awal peserta.

3. Pelaksanaan kegiatan pemberian materi bendung dan bendungan.

4. Pelaksanaan kegiatan pemberian materi Irigasi dan bangunan-bangunannya.

5. Pemberian materi petak tersier dan pemetaan jaringan irigasi.

6. Pemberian materi jalan dan jembatan.

7. Kunjungan lapangan jaringan irigasi beserta petak tersier.

8. Kunjungan lapangan bangunan utama, bendung, dan bendungan.

9. Pelaksanaan post-tes untuk mengetahui kemampuan akhir peserta setelah pelaksanaan kegiatan serta pemberian angket respon peserta terhadap kegiatan PKM.

\section{PELAKSANAAN DAN HASIL KEGIATAN}

Survey awal dilakukan untuk melihat sejauh mana pemahaman awal responden sebelum pelaksanaan PKM terhadap pemahaman dan kemampuan guru memahami materi yang akan diberikan. Setelah kegiatan pelaksanaan PKM, survey kembali dilakukan untuk mengukur tingkat pemahaman responden setelah pelaksanaan 
kegiatan PKM serta menjadi ukuran efektifitas pelaksanaan PKM kepada guru-guru SMK Program Keahlian Teknik Konstruksi dan Properti.

Hasil survey menunjukkan bahwa peserta yang mengikuti kegiatan ini adalah dominan belum mengikuti Pendidikan profesi guru, namun dominan dari mereka telah mengikuti pelatihan penerapam Kurikulum 2013. Namun demikian, penerapan pembelajaran spektrum SMK 2016 terutama terkait dengan pembelajaran yang menerapkan High Order Thinking Skill (HOTS) memang diharapkan berlaku sejak adanya revisi kurikulum 2013 (Armiwati et al. 2019).

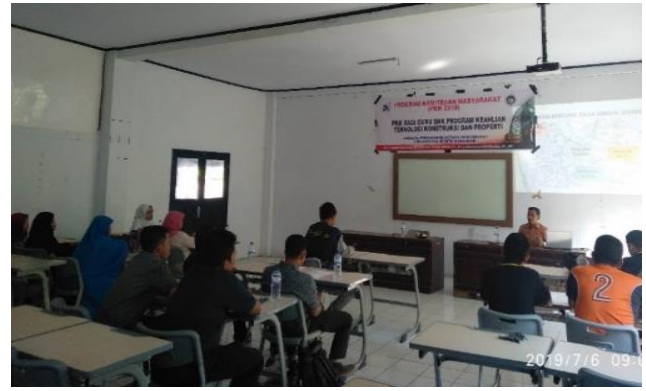

Gambar 1. Pemberian pre-test dan materi pelatihan

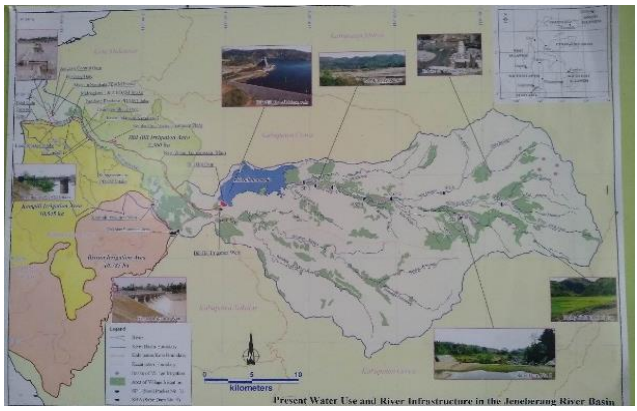

Gambar 2. Materi pelatihan peta Daerah Aliran Sungai Jeneberang

Gambar 1 dan 2 menunjukkan awal kegiatan pelaksanaan PKM. Kegiatan tersebut diawali dengan penjelasan tujuan kegiatan dan jadwal pelaksanaan kegiatan. Setelah itu, dilakukan pemberian pre-tes untuk mengukur pemahaman awal peserta pelatihan. Tim pelaksana selanjutnya menjelaskan materi pelatihan beserta rangkaian kegiatan yang menjadi target utama kegiatan PKM. Keterkaitan materi dengan mata pelajaran yang diajarkan sangat menghidupkan proses pembelajaran yang dilakukan. Hal ini mengindikasikan bahwa peserta sangat antusias dalam kegiatan PKM.
Selain itu, peserta juga merasa butuh akan materi tersebut sehingga proses tanya jawab berlangsung secara terus menerus.

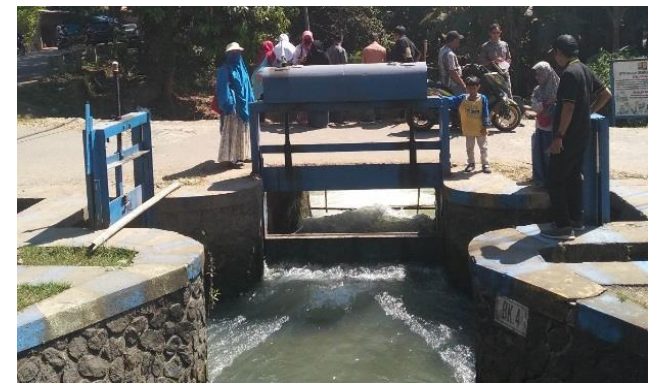

Gambar 3. Observasi bangunan utama dan bangunan pelengkap irigasi

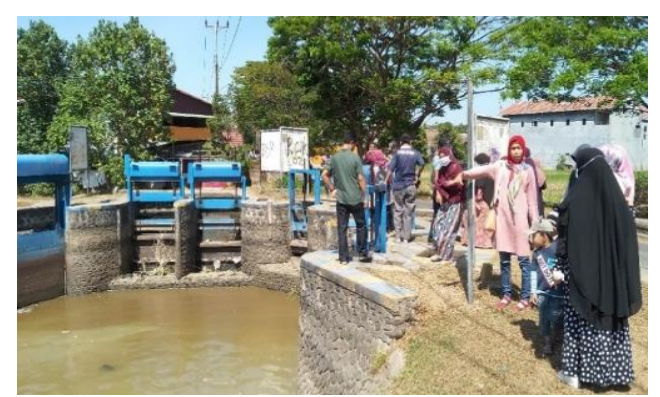

Gambar 4. Observasi pintu air dan petak tersier

Setelah pemberian materi oleh tim pelaksana kegiatan, selanjutnya dilaksanakan kunjungan pada lokasi pada Daerah Irigasi Kampili, Daerah Irigasi Bissua, dan Daerah Irigasi Bili-bili. Ketiga daerah irigasi tersebut mendapatkan suplay air dari sungai Jeneberang yang melintasi Kabupaten Gowa dan Kota Makassar. Pada sungai Jeneberang ini pula terletak Bendungan Bili-bili yang berada di hulu ketiga bending tersebut di atas.

Gambar 3 merupakan lokasi dimana terdapat saluran sekunder Kalukuang dan bangunan irigasi. Bangunan Kalukuang 4 (BK.4) merupakan bangunan bagi yang berfungsi membagi air dari saluran sekunder Kalukuang ke saluran sekunder Pare-Pare (Pr) dan saluran sekunder Labbakkang (Lb.). Di Lokasi ini juga terdapat Bangunan pelengkap berupa jembatan dan bangunan terjun.

Gambar 4 merupakan kunjungan pada Bangunan Limbung 14 (BL.14) yang berada pada saluran primer limbung. BL.14 merupakan bangunan bagi sadap yang berfungsi membagi air dari saluran primer limbung ke beberapa saluran sekunder serta 
saluran tersier. Saluran sekunder yang mendapat suplai air dari BL.14 yaitu saluran sekunder Kalukuang, saluran sekunder Majannang, dan saluran sekunder Doang. Selain itu, air irigasi juga masih berlanjut pada saluran primer limbung hingga mencapai BL. 17.

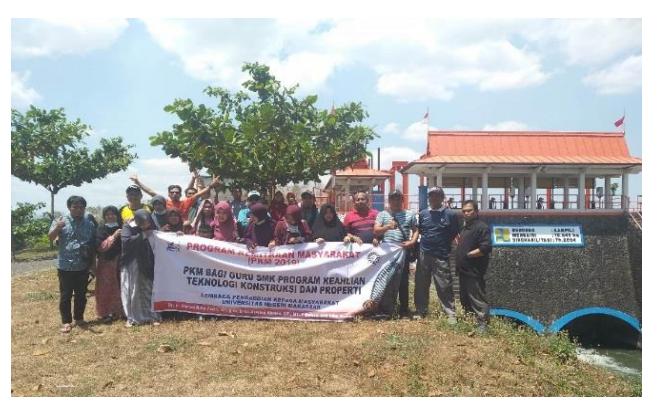

Gambar 5. Observasi Bangunan Bendung Kampili

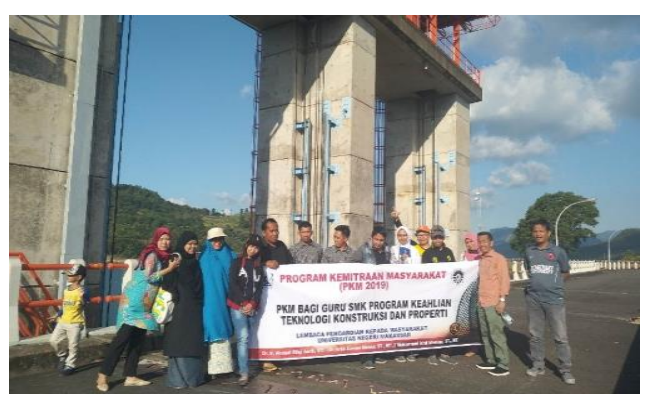

Gambar 6. Observasi Bangunan Bendungan Bili-bili

Kegiatan pada hari berikutnya adalah kunjungan pada bangunan utama jaringan irigasi, yakni Bendung Kampili, Bendung Bissua, Bendung Bili bili, dan Bendungan Bili-bili. Pada Gambar 5 adalah kegiatan kunjungan pada Bendung Kampili. Pada lokasi ini, peserta dijelas-kan berbagai hal mengenai bending mulai dari sejarah pembuatan bendung, bagian utama dan pelengkap dari bending, hingga kondisi yang terjadi di lokasi bendung ketika terjadi bencana banjir. Hal ini juga dilakukan pada saat mengunjungi Bendung Bissua dan Bendung Bili-bili.

Pada Gambar 6, merupakan kunjungan hari terakhir pada Bendungan Bili-bili. Bendungan ini dibangun dengan menenggelamkan beberapa desa sebagai lokasi penampungan air bendungan. Bendungan Bili-bili dibangun dengan bantuan pinjaman dari pemerintah Jepang. Bendungan ini berfungsi untuk mengendalikan banjir yang sering terjadi, pemenuhan cadangan air untuk irigasi, pembangunan pembangkit listrik tenaga air (PLTA), penyediaan air bersih, dan beberapa fungsi lainnya (Asrib et al., 2019; Jamaluddin 2018).

Setelah rangkaian kegiatan PKM dilaksanakan, maka diakhir kegiatan peserta diberi angket kembali sebagaimana angket pemahaman peserta ketika kegiatan PKM belum dilaksanakan. Hasil pelaksanaan PKM menunjukkan data sebagai berikut (Tabel 1).

Dari Tabel 4.1 terlihat bahwa sebagian besar guru telah hanya memahami materi irigasi pada kategori Cukup, namun terdapat rerata 12 persen guru yang pemahamannya masih sangat kurang. Para guru juga belum ada yang mampu membedakan bangunan-bangunan irigasi dengan sangat baik. Setelah pelaksanaan kegiatan PKM, para guru peserta kegiatan mengalami peningkatan pemahaman yang sangat signifikan. Pemahaman guru dari kategori sangat baik sebesar $4.36 \%$ menjadi $41.28 \%$. Kategori Baik dari $20.00 \%$ menjadi $55.64 \%$ bahkan setelah kegiatan, tidak ada lagi guru yang tidak memahami materi mengenai irigasi dan bangunan-bangunannya. 
Tabel 4.1 Pemahaman guru mengenai materi

\begin{tabular}{|c|c|c|c|c|c|c|c|c|}
\hline \multirow[b]{2}{*}{ Uraian } & \multicolumn{4}{|c|}{ Sebelum Kegiatan } & \multicolumn{4}{|c|}{ Setelah Kegiatan } \\
\hline & $\begin{array}{l}\text { Sangat } \\
\text { Baik }\end{array}$ & Baik & Cukup & $\begin{array}{l}\text { Sangat } \\
\text { Kurang }\end{array}$ & $\begin{array}{l}\text { Sangat } \\
\text { Baik }\end{array}$ & Baik & Cukup & $\begin{array}{l}\text { Sangat } \\
\text { Kurang }\end{array}$ \\
\hline Membedakan Bendung dan Bendungan & 7.69 & 11.54 & 69.23 & 11.54 & 57.69 & 42.31 & 0.00 & 0.00 \\
\hline $\begin{array}{l}\text { Memahami bagian-bagian dari Bangunan } \\
\text { Utama }\end{array}$ & 3.85 & 23.08 & 65.38 & 7.69 & 50.00 & 46.15 & 3.85 & 0.00 \\
\hline Memahami fungsi Irigasi & 3.85 & 26.92 & 65.38 & 3.85 & 53.85 & 46.15 & 0.00 & 0.00 \\
\hline Menguraikan Jaringan Irigasi & 3.85 & 19.23 & 69.23 & 7.69 & 34.62 & 65.38 & 0.00 & 0.00 \\
\hline Memahami Pengertian Daerah Irigasi & 7.69 & 26.92 & 61.54 & 3.85 & 42.31 & 57.69 & 0.00 & 0.00 \\
\hline $\begin{array}{l}\text { Mendeskripsikan Bangunan Bagi pada } \\
\text { Jaringan Irigasi }\end{array}$ & 3.85 & 23.08 & 61.54 & 11.54 & 46.15 & 53.85 & 0.00 & 0.00 \\
\hline $\begin{array}{l}\text { Mendeskripsikan Bangunan Sadap pada } \\
\text { Jaringan Irigasi }\end{array}$ & 0.00 & 19.23 & 69.23 & 11.54 & 38.46 & 57.69 & 3.85 & 0.00 \\
\hline $\begin{array}{l}\text { Mendeskripsikan Bangunan Bagi Sadap } \\
\text { pada Jaringan Irigasi }\end{array}$ & 0.00 & 23.08 & 65.38 & 11.54 & 30.77 & 65.38 & 3.85 & 0.00 \\
\hline $\begin{array}{l}\text { Membedakan saluran primer, sekunder, } \\
\text { dan tersier }\end{array}$ & 3.85 & 30.77 & 57.69 & 7.69 & 57.69 & 38.46 & 3.85 & 0.00 \\
\hline $\begin{array}{l}\text { Menjelaskan berbagai alat pengatur dan } \\
\text { pengukur }\end{array}$ & 3.85 & 11.54 & 65.38 & 19.23 & 19.23 & 80.77 & 0.00 & 0.00 \\
\hline Memahami Petak Tersier & 3.85 & 15.38 & 65.38 & 15.38 & 42.31 & 53.85 & 3.85 & 0.00 \\
\hline Memahami Peta Jaringan Irigasi & 3.85 & 15.38 & 57.69 & 23.08 & 26.92 & 61.54 & 11.54 & 0.00 \\
\hline Memahami Skema Jaringan Irigasi & 7.69 & 11.54 & 61.54 & 19.23 & 30.77 & 65.38 & 3.85 & 0.00 \\
\hline $\begin{array}{l}\text { Membedakan Bangunan Talang dan } \\
\text { Syphon }\end{array}$ & 7.69 & 19.23 & 57.69 & 15.38 & 53.85 & 46.15 & 0.00 & 0.00 \\
\hline Menjelaskan Bangunan Terjun & 3.85 & 23.08 & 57.69 & 15.38 & 34.62 & 53.85 & 11.54 & 0.00 \\
\hline Rerata & 4.36 & 20.00 & 63.33 & 12.31 & 41.28 & 55.64 & 3.08 & $\mathbf{0 . 0 0}$ \\
\hline
\end{tabular}

\section{KESIMPULAN}

Dari hasil kegiatan program kemitraan masyarakat, dapat disimpulkan bahwa Guru SMK program keahlian Teknik Konstruksi dan Properti telah memahami dengan baik materi irigasi dan bangunan-bangunannya sesuai Spektrum SMK 2016.

\section{UCAPAN TERIMA KASIH}

Tim pelaksana kegiatan mengucapkan terima kasih kepada Fakultas Teknik melalui DIPA Universitas Negeri Makassar yang telah memberi bantuan pendanaan sehingga kegiatan ini terlaksana dengan sangat baik.

\section{DAFTAR PUSTAKA}

Arfandi, Anas, and Onesimus Sampebua. 2018. "The Study of Vocational Higher Education Graduates Skills That Requires in Industry." Advanced Science Letters 24(5): 3632-35.
Armiwati, Anas Arfandi, Nur Anny S Taufieq, and Arianti. 2019. "Penyusunan Butir Soal Formatif Dan Sumatif Berbasis HOTS Pada Mata Pelajaran Estimasi Biaya Konstruksi Dan Properti Di SMK Negeri 4 Gowa." In Prosiding Seminar Nasional Fakultas Teknik UNM,.

Asrib, Ahmad Rifqi, and Anas Arfandi. 2017. "Meeting the Industrial Demand of Construction Engineering Gradu ate Competence." Jurnal Pendidikan Vokasi 7(3): 320-28.

Asrib, Ahmad Rifqi, Anas Arfandi, Gufran D Dirawan, and Fajriana Haryadi. 2019. "Analy sis Test of Fine Aggregates at the Upstream of Jeneberang River." In Journal of Physics: Conference Series, IOP Publishing, 12039.

Hadi, S, D Andrian, and B Kartowagiran. 2019. "Evaluation Model for Evaluating Vocational Skills Programs on Local Content Curriculum in Indonesia: Impact of Educational System in Indonesia." Eurasian Journal of Educational Research 2019(82): 45-62.

Jamaluddin, Jamaluddin. 2018. "Bendungan Bili-Bili 19922016." Phinisi Integration Review 1(2): 112-27.

Nilasari, Y, and Dasining. 2018. "Curriculum Development Based on INQF and Business/Industries Sector for Improvement Competency of Basic Pattern Making Students at Vocational High School." In eds. Peni H., Puspitaningayu P., and Rakhmawati L. Graduate Program, Universitas Negeri Surabaya, Indonesia: Institute of Physics Publishing. 
Purnamawati. 2018. "Needs Analysis of Vocational High School Partnership Model with World Business and Industry in Makassar." In Department of Electronic Engineering Education, Universitas Negeri Makassar, Makassar, 90222, Indonesia: Institute of Physics Publishing.

Retnawati, H, S Hadi, and A C Nugraha. 2016. "Vocational High School Teachers' Difficulties in Implementing the
Assessment in Curriculum 2013 in Yogyakarta Province of Indonesia." International Journal of Instruction 9(1): 33-48.

Widiaty, Isma. 2013. "Relevansi Kurikulum SMK Berbasis Industri Kreatif Dengan Metode Extrapolation and the Econometric Approach." Innovation of Vocational Technology Education 9(1). 